\title{
Adjuvant drugs in management of osteoarthritis: spotlight on type II collagen
}

\author{
Vijay Kakatkar ${ }^{1}$, A. K. Pal ${ }^{2}$, Raghuveer Reddy ${ }^{3}$, Ravi Dashputra ${ }^{4}$, \\ Sanjay Kamble ${ }^{5}$, Hiten Saresa ${ }^{5}$, Rishi Jain ${ }^{5}$
}

\begin{abstract}
Department of Orthopaedics, ${ }^{1}$ Ramkrishna Medical Research Centre, Nashik, Maharashtra, ${ }^{2}$ SSKM Medical College, IPGMER, Kolkata, West Bengal, ${ }^{3}$ Sai Institute of Sports Injury and Arthroscopy, Hyderabad, Telangana, ${ }^{4}$ Dashputra Orthopedic Hospital, Nagpur, Maharashtra, India

${ }^{5}$ Department of Medical Affairs, Wockhardt Ltd., BKC, Mumbai, Maharashtra, India
\end{abstract}

Received: 29 March 2019

Revised: 18 May 2019

Accepted: 30 May 2019

\section{*Correspondence:}

Dr. Sanjay Kamble,

E-mail: skamble@wockhardt.com

Copyright: (c) the author(s), publisher and licensee Medip Academy. This is an open-access article distributed under the terms of the Creative Commons Attribution Non-Commercial License, which permits unrestricted non-commercial use, distribution, and reproduction in any medium, provided the original work is properly cited.

\begin{abstract}
Osteoarthritis (OA) is a common musculoskeletal disorder that affects large and small joints and is seen in all ages due to diverse aetiologies. Pain, joint stiffness and limitation of daily activities affects the quality of life of individuals with OA. Conventional analgesics like non-steroidal anti-inflammatory drugs affect pain and inflammatory component but do not target the disease pathogenesis. Damage to the joint cartilage is central to the pathogenesis of OA. Better understanding of the pathogenesis has led to evolution of various adjuvant drugs in management of OA. Among them, undenatured type II collagen induces immune tolerance and thereby provide benefits by reducing the joint damage. Studies assessing efficacy and safety of undenatured type II collagen in OA have shown to reduce clinical symptoms like pain, joint stiffness and improvement in physical activities, and thus improving the quality of life. It is well tolerated and safe for use in OA. This article discusses the pathophysiology of OA with inflammation and beyond, and overviews the various drugs that are used as adjuvants in the management of OA with special focus on the use of type 2 collagen.
\end{abstract}

Keywords: Type II collagen, Osteoarthritis, Inflammation, Pain, Quality of life, Adjuvant

\section{INTRODUCTION}

Osteoarthritis (OA) is the most common musculoskeletal degenerative disorder of articular cartilage that predominantly affects the weight-bearing joints (e.g. knees, hips, cervical and lumbosacral spine and feet). Recent pathological understandings elaborate that OA is not restricted to the articular cartilage but involves entire joint including the subchondral bone and synovium and thus it is defined as a collection of overlapping distinctive joint disorders which result in similar biological, morphological and clinical outcomes. ${ }^{1}$ Interplay of various risk factors such as increasing age, obesity, joint malalignment, increased biomechanical loading of joints, genetics and as recently suggested, low-grade systemic inflammation are instrumental in OA. ${ }^{2}$ Alterations in the articular cartilage, subchondral bone, ligaments, capsule and synovial membrane lead to loss of cartilage, osteophyte formation, subchondral bone changes and meniscal alterations. ${ }^{3,4}$ This is associated with clinical symptoms of chronic pain, joint in-stability, stiffness and radiographic joint space narrowing. ${ }^{5}$ Chronic low-grade joint inflammation and genetic predisposition have been identified as risk factors in OA. ${ }^{6}$ 
The quality of life is impaired due to persistent pain and difficulties in routine activities like stair climbing, squatting, etc. ${ }^{7}$ Therefore, effective management of OA is necessary to improve the quality of life. OA is treated mainly by exercise along with the use of analgesics like non-steroidal anti-inflammatory drugs (NSAIDs). These medications though relieve the symptoms, do not play disease modifying role and are associated with increased risk of adverse effects over long term use. During last few decades, disease-modifying osteoarthritis drugs (DMOADs) have received increasing interest. These new drugs are aimed at preventing or diminishing the deterioration of joint tissue. Recent studies on treatment with undenatured type II collagen demonstrated improvement in pain and motion of knee joint. ${ }^{8,9}$ With its possible effect of modulation of inflammation, undenatured type II collagen can affect the disease pathogenesis and may prevent joint damage in OA. ${ }^{10}$ In this article, we discuss the pathogenesis, gaps in clinical treatment and the current evidence on utility of adjuvant drugs in management of OA with special reference to undenatured type II collagen.

\section{EPIDEMIOLOGY OF OA}

The 2010 global burden of disease study reports that the burden of musculoskeletal diseases account for $6.8 \%$ of disability-adjusted life years (DALYs) worldwide. $^{11}$ According to the United Nations, by 2050 people aged over 60 will account for more than $20 \%$ of the world's population, and among them nearly $15 \%$ will have symptomatic OA, and one-third will become severely disabled. These data indicate that by 2050 , about 130 million people across the globe will suffer from OA, of whom 40 million will be severely disabled by the disease. ${ }^{12}$ From India, recent, large sample observational study reported that the prevalence of OA was $27.1 \%$. Further, it was observed that the prevalence of OA was higher in villages $(31.1 \%)$ and big cities $(33.1 \%)$ than towns $(17.1 \%)$ and small cities $(17.2 \%) .{ }^{13}$ This colossal presence of OA demand consideration of methodical approaches for management of pan-joint pathology in OA.

\section{ROLE OF INFLAMMATION IN PATHOPHYSIO- LOGY OF OA}

In OA, changes are seen in composition and structure of the cartilage matrix. In early phase of the disease, minor fibrillations appear on the surface proceeding to the deep fissures with disease progression leading to exfoliation of articular cartilage. Delamination and denudation of the underlying layer of calcified cartilage and bone is seen. Further, growth of the zone of calcified cartilage and substitution of the overlying articular cartilage is also observed. ${ }^{14}$ Osteogenesis in the perivascular space ensues the endochondral bone formation. ${ }^{15}$ Chronic low-grade inflammation plays an important role in development and progression of OA. Multiple factors such as physical inactivity, predisposing risk factors, inflammatory processes, obesity and altered joint biomechanics, are instrumental in pathogenesis of OA (Figure 1). Pathogenetically, entire synovial joint including cartilage, subchondral bone and synovium, are involved in the inflammatory process. ${ }^{16}$ Synovitis is associated with changes such as synovial hyperplasia and diffuse perivascular infiltrates of $B$ lymphocytes and $T$ lymphocytes. The multitude of pathologic cascade of molecular activations involving damage associated molecular patterns (DAMPs) increases the expression of inflammatory and catabolic pathways and lead to cartilage damage. ${ }^{17}$ Receptor expression for various chemokines like matrix metalloproteinases (MMPs) and "a disintegrin and metallo-protease with thrombospondin motifs" (ADAMTS) on the chondrocytes and the synovial cells suggests their potential contribution to synovitis. $^{16,18}$

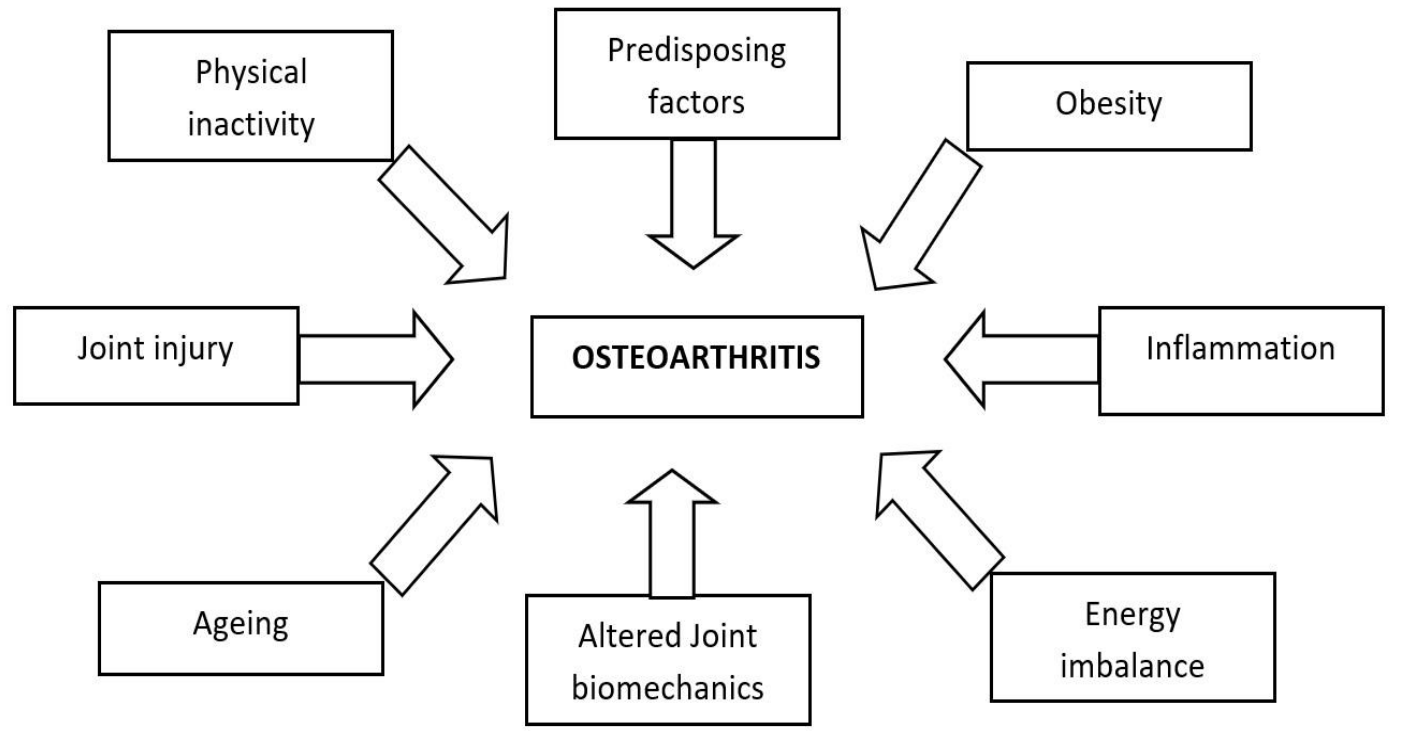

Figure 1: Pathophysiological aspects in osteoarthritis. 


\section{OSTEOARTHRITIS: LOOK BEYOND INFLAM- MATION}

There is a striking balance between the anabolic and catabolic processes that occurs in chondrocytes and synovial fluid of the joints. ${ }^{19}$ Various molecular mechanisms and growth factors, including transforming growth factor- $\beta$ (TGF- $\beta$ ) and other signalling molecules are implicated in onset and progression of OA. ${ }^{18,20}$ Runx2 is a transcription factor responsible for direct regulation of the gene transcription that encode degradation enzymes in matrix of articular chondrocytes. ${ }^{21}$ These findings necessitates preventive and therapeutic interventions to prevent $\mathrm{OA}$ and/or improve the regeneration capacities of joint cartilage. In the view of this imbalance of 'anabolic-catabolic see-saw' in pathophysiological evolution of OA (Figure 2), it makes clinical sense to approach the disease pathology. Since nutraceuticals have a role in anabolic and catabolic signals in joints, they should be considered for the management and prevention of $\mathrm{OA}^{22}$ When used as adjunctive therapy, they potentially can help to improvise the treatment options for patients with established OA beyond traditional rehabilitation, medications and surgical strategies.

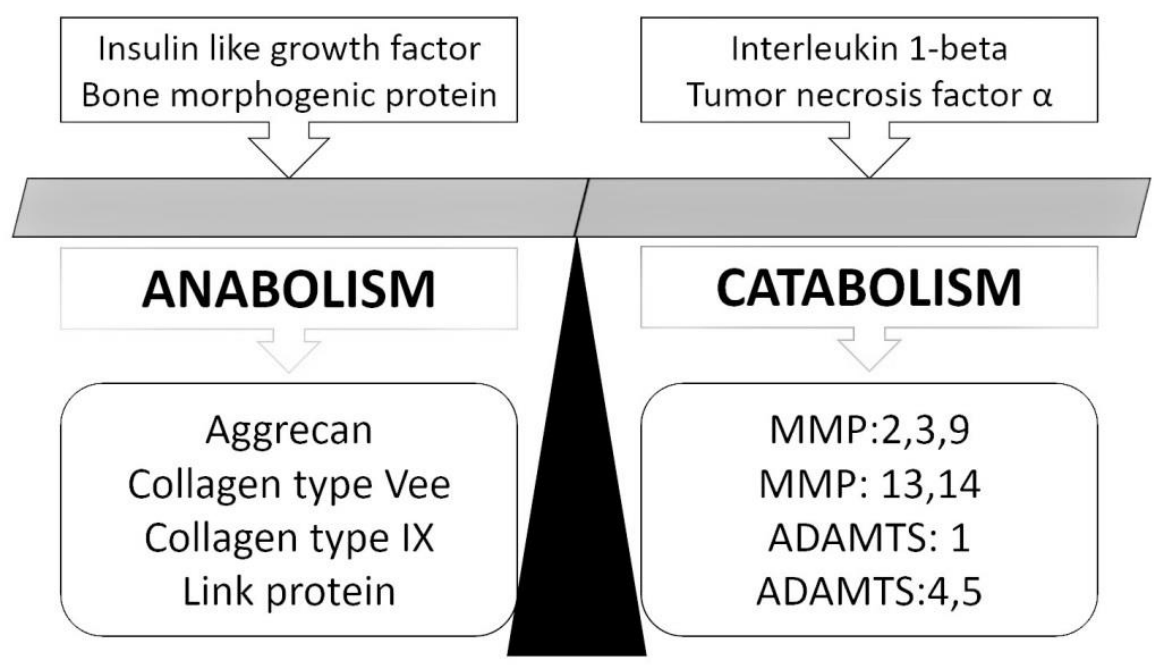

Figure 2: The cartilage turnover mechanisms in osteoarthritis. ADAMTS: a disintegrin and metalloproteinase with thrombospondin motifs; MMP: matrix metalloproteins.

\section{CURRENT MANAGEMENT OF OA AND THERA- PEUTIC NEEDS}

Management of OA has been elaborated by evidencebased guidelines from various prominent musculoskeletal organizations across globe. The anatomical location and number of joints affected by OA seems to influence the efficacy of therapy. Often, it is seen that in clinical trials conducted on knee joint, OA is a major contributor for generation of majority of the evidence-base for these guidelines formulation. Current strategies for treatment of OA include non-pharmacological interventions such as exercise, heat/cold therapy, joint protection, weight loss, physiotherapy/occupational therapy and pharmacological intervention with medications. For advanced OA, surgical interventions like joint replacement is indicated. ${ }^{23}$ Combination of these multiple therapies are frequently used by clinicians for people affected by OA.

\section{Non-pharmacological interventions}

A patient-centred multidisciplinary, tailor-made combination of education, self-management, regular joint-exercises, weight management with realistic goals, encouragement and periodic reassessment are current non-pharmacologic recommendations for osteoarthritic patients. Cochrane review suggests land-based exercise programs for hip and knee, owing to the improvement in physical function and pain by these practiced programs. But there is still lack of strong evidence to indicate the effectiveness of hand exercises in reduction of pain in OA of the hand. ${ }^{24}$

\section{Pharmacological interventions}

Pharmacological treatments in various formulations and route of administrations such as topical, oral and injectable are available. Factors like age, concurrent medications, comorbid conditions (e.g. cardiovascular disease and gastrointestinal conditions) and predicted compliance and adherence can affect the individual treatment. So, these factors need to be considered before beginning with the pharmacological intervention. Existing therapies include mostly the moderately effective pain relievers. It is important to note that, despite of adherence to all prescribed drugs in adequate dosage, pain persists in most people. First-line pharmacotherapies usually are topical NSAIDs and oral paracetamol. ${ }^{25}$ Due to local application, topical NSAIDs confer better safety profiles than oral NSAIDs as systemic drug levels attained are minimal. However, owing to their improper and limited joint penetration and 
multiple daily applications, their usage is far from being effectively ideal. Paracetamol is perhaps, a less effective analgesic in OA than NSAIDs. ${ }^{26}$ Opioid analgesic usage is variable across different nations, but usually they often remain the last option for people who are unable to tolerate NSAIDs. Albeit, opioid analgesics have their own significant toxicity profile.

\section{ADJUVANT AGENTS IN MANAGEMENT OF OA}

Adjuvant agents are often prescribed with NSAIDs in OA patients in routine practice. They are given as add on therapy with the mainstay drug or as follow up in the maintenance phase. These agents include nutraceuticals agents obtained from natural sources that play a significant role in management of OA. These products consist of glycosaminoglycans (GAG) unit components and GAGs, such as chondroitin sulphate and glucosamine. European Society for Clinical and Economic Aspects of Osteoporosis, Osteoarthritis and Musculoskeletal Diseases (ESCEO) guidelines and Cochrane reviews suggest that these therapies may have analgesic effects beyond the placebo effect. ${ }^{27,28}$ Existing treatment guidelines feature NSAIDs and paracetamol as the most commonly used medications in the management of OA. Although these drugs are some-what effective for pain reduction associated with $\mathrm{OA}$, they have no role in addressing the pathophysiology and reversing the disease. In addition, there are concerning side effects associated with the long-term use of these drugs. This forms the basis to use nutraceuticals as adjuvant agents for relief of pain and discomfort in OA. As of now, chondroitin and glucosamine are the two most widely used adjuvant agents in humans as well as in animals to alleviate pain associated with arthritis. These are natural products that can be used for long-term as they are well tolerated and are considerably safe.

\section{S-Adenosyl methionine}

S-Adenosyl methionine (SAMe) has been used for OA since long but its exact mechanism of providing analgesia in OA remains unknown. It has been proposed to reduce inflammation, and increase proteoglycan synthesis. A better tolerability has been an advantage of SAMe compared to conventional analgesics like NSAIDS. ${ }^{29}$ It has shown equivalent analgesic efficacy to that of COX-2 inhibitor after 2 months of treatment. ${ }^{30}$

\section{Glucosamine sulphate / Chondroitin sulphate}

These are the common adjuvants that are being used either alone or in combination for the management of OA. Its protective effect has been postulated to be due to potential antioxidant activity in scavenging the free radicals. A large prospective trial with individual salts and their combination in patients of OA reported no significant difference in pain reduction with individual agents in comparison to placebo. However, combination treatment was associated with higher rate of response (reduction of $20 \%$ in knee pain by 24 weeks) than placebo $(79.2 \%$ vs $54.3 \%, \mathrm{p}=0.002) .{ }^{31} \mathrm{~A}$ recent metaanalysis from Zhu et al involving 30 studies reported that chondroitin when compared to placebo can alleviate pain and improve the function but glucosamine only improved the stiffness. Efficacy of combination treatment was not found to be superior to placebo because of low number of studies with combination. ${ }^{32}$

\section{Botanical extracts}

\section{Scutellaria baicalensis and Acacia catechu extracts}

Scutellaria baicalensis have been used in many Asian countries for treatment of cold and bacterial pneumonia. The root extract is said to possess antioxidant activities scavenging free radicals. Baicalin from $S$. baicalensis and catechin from A. catechu possess COX and LOX inhibition activity that may provide analgesic effects in OA. It has also been suggested to provide improvement in cartilage matrix integrity. ${ }^{33}$ These effects probably have translated to clinical benefits. A study from Arjmandi et al reported that the combination of extracts from two plants was associated with significant reduction in perceived pain, stiffness and mean range of motion after one-week treatment. Comparatively, naproxen treatment showed only reduction in knee joint stiffness. ${ }^{34}$ However, further large, controlled studies are necessary to establish these benefits.

\section{Green tea (Camellia sinensis)}

A recent open-label randomized trial from Hashempur et al compared green tea extract and diclofenac oral to diclofenac alone in patients with knee OA. It was observed that compared to monotherapy, the combination group showed significant reduction in VAS pain score, total WOMAC and WOMAC physical function scores, however WOMAC pain and WOMAC stiffness scores were found to be non-significant. ${ }^{35}$ This suggests green tea extract can play adjunctive role in knee OA.

\section{Curcumin}

It is a yellow pigment isolated from the rhizomes of Curcuma longa and has shown efficacy in OA in some clinical studies. ${ }^{36}$

\section{Black pepper (Piper nigrum)}

In lieu of its anti-inflammatory properties, it has shown to reduce the IL-1 $\beta$-induced over-expression of inflammatory mediators like MMP-3, MMP-13, iNOS and $\mathrm{COX}-2$ in human $\mathrm{OA}$ chondrocytes suggesting its potential utility in $\mathrm{OA} .^{37}$

\section{Boswellia Serrata}

It possesses four pentacyclic triterpenic acids of which acetyl-11-keto- $\beta$-boswellic acid is the most potent 
inhibitor of 5-lipoxygenase enzyme providing effective anti-inflammatory properties. ${ }^{38}$ A novel synergistic composition of $20 \%$ AKBA enriched B. serrata nonvolatile oil has shown efficacy in OA. ${ }^{39}$

\section{Withania somnifera}

Compared to placebo, root extract of W. somnifera in doses $250 \mathrm{mg}$ and $125 \mathrm{mg}$ showed significant reductions in mean modified WOMAC score, Knee Swelling Index and VAS scores for pain, stiffness and disability. ${ }^{40}$

\section{Zingiber officanalis}

Ginger is known to inhibit the cox enzyme resulting in anti-inflammatory effects. A meta analysis with final 5 moderate quality trials reported a significant pain reduction [standardized mean difference (SMD)-0.30 (95\% CI $\left.(-0.50,-0.09), \mathrm{P}=0.005, \mathrm{I}^{2}=27 \%\right)$ and significant reduction in disability (SMD-0.22 (95\% CI $\left.(-0.39,-0.04) \mathrm{P}=0.01 ; \mathrm{I}^{2}=0 \%\right)$ with ginger intake than placebo. However, a greater likely chance of discontinuation with ginger intake led to conclusion that ginger is modestly effective and reasonably safe in OA. ${ }^{41}$

\section{Fish oil}

Being rich in omeg-3 fatty acids, fish oil has been explored for its use in OA. The effects are mediated by reducing release of pro-inflammatory mediators and increase in joint lubrication. However, the human clinical studies have not shown consistently significant benefit to substantiate or refute its utility in OA. ${ }^{42}$ Recent study from Hill et al compared the high-dose fish oil (4.5 gm omega-3 fatty acids) to a blend of low dose (0.45 gm omega-3 fatty acids) fish oil and sunola oil (ratio 1:9) administered as $15 \mathrm{ml} / \mathrm{d}$ in knee OA. They observed that low-dose group showed greater improvement in pain and function at 2 years. This necessitates further investigation on sunola oil in combination with fish oil. ${ }^{43}$ This opened up new perspectives on use of fish oil in OA. Despite these evidences, there is a need to further substantiate its efficacy in OA in a large randomized trial.

\section{Olive oil}

It is one of constituent of the Mediterranean diet has shown to possess antioxidant and anti-inflammatory activity due to presence of phenolic compounds and monounsaturated fatty acids. A pilot study reported improvement in knee pain and function after topical application of olive oil. ${ }^{44}$ However, this needs confirmation in larger study.

\section{Avocado/soybean unsaponifiable (ASU)}

By virtue of different properties, ASU prevents cartilage degradation, inhibits fibrinolysis, promote cartilage repair and exerts chondroprotection. ${ }^{45}$ A 3 years RCT in hip OA patients established that there were $20 \%$ less progressors (minimum joint space width (JSW) loss $\geq 0.5 \mathrm{~mm}$ ) in the ASU-E than in the placebo group $(40 \%$ vs $50 \%$, respectively, $\mathrm{p}=0.040$ ). This suggests that there may be a structure modifying effect in hip OA with ASU. ${ }^{46}$

\section{UNDENATURED TYPE II COLLAGEN}

\section{Role of collagen in joint physiology and OA pathology}

Collagen fibrils makes the structural backbone of cartilage matrix and is mainly composed of type II collagen. Extracellular matrix also contains type IX collagen on the surface of the fibril. ${ }^{47}$ Overt articular degeneration presents initially at the surface and then extend in to deeper layers that damages proteoglycans decorin, biglycan, and aggrecan. ${ }^{48}$ A quantifiable decrease in type II collagen denaturation is evident in early OA resulting in net loss of this important structural support molecule. ${ }^{49}$ Thus, collagen derivatives seem to be effective candidates to be considered as disease modifying osteoarthritic drugs (DMOADs). In this regard, collagen derivatives are currently being investigated in preclinical and clinical trials. The three major groups of collagen derivatives viz; undenatured collagen (UC), gelatine and collagen hydrolysate $(\mathrm{CH})$ are described. ${ }^{50}$

\section{Mechanism of action}

Undenatured type II collagen is studied predominantly in osteoarthritis (OA) patients. It is described to have a working mechanism called oral immune tolerance, i.e. by causing diminution of autoimmune response against collagen of articular cartilage ${ }^{50} \mathrm{CH}$ and gelatine differ to undenatured type II collagen in their bioavailability. ${ }^{51}$

Experimental evidence indicates even in microgram quantities, undenatured type II collagen is enough for the induction of $\mathrm{T}$ regulator cells. ${ }^{52}$ In response to the oral administration of undenatured type II collagen, the induction of these $\mathrm{T}$ regulators take place within gut associated lymphatic tissues (GALT), including mesenteric lymph nodes. Studies have demonstrated that these regulatory cells produce IL-10 and TGF- $\beta{ }^{53,54} \mathrm{~A}$ unique class of CD103+ dendritic cells, found almost exclusively in the GALT, facilitates this process. ${ }^{55}$ Upon activation, $\mathrm{T}$ regulator cells seem to downregulate a wide range of immunologic and proinflammatory downstream cascades resulting in the control of the arthritic response. This phenomenon of oral tolerance has also been established in humans and appears to involve a similar set of T regulators mechanisms. ${ }^{56}$ These mechanisms indicate the central and pivotal role of collagen therapy in tailoring management strategies for OA.

\section{Experimental evidence}

A study in the rat model of osteoarthritis reported several benefits after treatment with undenatured type II collagen including preservation of weight bearing capacity of the injured leg and integrity of cancellous bone suggesting 
potential for prevention of worsening of articular cartilage damage. ${ }^{57}$ In another study, effect of porcine native type II collagen was studied in the rat model of OA. After two weeks, porcine native type II collagen showed a significant prevention of pain threshold alterations induced by sodium monoiodoacetate (MIA). Reduction in pain was higher with lowering of dose. There was also reduction in plasma and urine levels of cartilage damage biomarker - cross-linked C-Telopeptide of type II Collagen (CTX-II). Low dosages of native type II collagen showed pain reduction and indicated protective effect on the cartilage. ${ }^{58}$

\section{Clinical evidence}

Various studies both in healthy subjects and OA diagnosed patients have demonstrated efficacy and safety of collagen therapy as described in Table 1.

A randomized, double-blind, placebo-controlled study was conducted in healthy subjects who had no prior history of arthritic disease or joint pain at rest but experienced joint discomfort with physical activity. ${ }^{59}$ Fifty-five subjects with knee pain after a standardized step mill performance test were randomized to receive placebo $(n=28)$ or undenatured type II collagen $(40 \mathrm{mg}$ daily, $n=27$ ). After 120 days of supplementation, subjects in the undenatured type II collagen group exhibited a statistically significant improvement in average knee extension compared to placebo $\left(81.0 \pm 1.3^{\circ}\right.$ vs $74.0 \pm 2.2^{\circ}$; $\mathrm{p}=0.011)$ and to baseline $\left(81.0 \pm 1.3^{\circ}\right.$ vs $73.2 \pm 1.9^{\circ}$; $\mathrm{p}=0.002)$. The undenatured type II collagen cohort also demonstrated a statistically significant change in average knee extension at day 90 compared to baseline $\left(78.8 \pm 1.9^{\circ}\right.$ vs $73.2 \pm 1.9^{\circ} ; \mathrm{p}=0.045$ ). Also, time duration of exercise without experiencing any initial joint discomfort was longer at day 120 than that of baseline $(2.8 \pm 0.5 \mathrm{~min}$ vs $1.4 \pm 0.2 \mathrm{~min}, \mathrm{p}=0.019)$. By contrast, they observed no significant changes in the placebo group. The study reported no product related adverse events. Study found that undenatured type II collagen was well tolerated and led to improved knee joint extension with potential to increase the period of pain free strenuous exertion and alleviate the joint pain that arises from such activities.

Another clinical trial compared safety and efficacy of undenatured type II collagen with combination of glucosamine and chondroitin $(\mathrm{G}+\mathrm{C})$ in the treatment of $\mathrm{OA}$ of the knee. The results demonstrated that undenatured type II collagen treatment was more efficacious resulting in a significant reduction in all assessments i.e. Western Ontario McMaster Osteoarthritis Index (WOMAC) score, Lequesne's functional index and 100-mm visual analog scale (VAS) pain scores from the baseline at 90 days; whereas, this effect was not observed in $\mathrm{G}+\mathrm{C}$ treatment group. ${ }^{7}$ Reduction of WOMAC score with undenatured type II collagen was $33 \%$ as compared to $14 \%$ in $\mathrm{G}+\mathrm{C}$ treated group after 90 days. Similar results were also obtained for visual analog scale (VAS) scores. Treatment with undenatured type II collagen reduced Lequesne's functional index score by $20 \%$ as compared to $6 \%$ in $\mathrm{G}+\mathrm{C}$ treated group. This demonstrates that undenatured type II collagen significantly improved the daily activities contributing to overall improvement of quality of life in OA.

Lerman et al carried out a nutritional approach for relief of joint discomfort in a form of a 12-week, open-case series and illustrative case report. ${ }^{60}$ This study evaluated the efficacy and safety of a proprietary tablet containing $150 \mathrm{mg}$ of $\mathrm{n}$-enriched Tetrahydroiso- $\alpha$ acids (nTHIAA) and $10 \mathrm{mg}$ of undenatured type II collagen in OA. Participants were administered two tablets of the combination per day with meals for 12 weeks. Participants completed arthritis related quality-of-life questionnaires [visual analogue scale for pain (VAS-P), the medical symptoms questionnaire (MSQ), the health and wellness outcome questionnaire (MOS-SF36), the arthritis impact questionnaire (AIQ), the health assessment questionnaire (HAQ-DI), the arthritis impact measurement scales 2 (AIMS2)] at weeks 2, 4, 8, and 12. At 12 week, participants also completed the visual analogue scale for efficacy (VAS-E). All participants completed the entire 12-week evaluation, and all of them reported improvements in pain. Significant improvements in scores on the questionnaires were observed as early as week 2. At baseline, 13 of the 17 participants were using analgesics for joint pain, compared with only 4 participants at 12 weeks. Two of those 4 participants had reduced their analgesic dosages. The studied supplement was well tolerated, and no serious side effects occurred. The authors concluded that supplement containing nTHIAA and UC-II is safe and efficacious in participants with chronic joint pain. Though the study reported pain improvements, it is uncertain that to what extent only undenatured type II collagen has provided this effect. Nonetheless, of the two components, it only seems to be the major effect driver.

Lugo et al in a double-blind study, randomized 190 patients with knee OA to daily dose of undenatured type II collagen (40 mg), GC (1500 mg G \& $1200 \mathrm{mg} \mathrm{C}$ ), or placebo. After 180-days treatment, undenatured type II collagen demonstrated significant reduction in overall WOMAC score compared to placebo $(\mathrm{p}=0.002)$ and $\mathrm{GC}$ $(\mathrm{p}=0.04)$. Supplementation with UC-II also resulted in significant changes for all three WOMAC subscales compared to placebo [pain (24.0 vs. 17.0; 95\% confidence interval (CI)-11.1 to-2.8; $\mathrm{p}=0.0003)$, stiffness (23.8 vs. $17.8 ; 95 \% \mathrm{CI}-10.4$ to $-1.6 ; \mathrm{p}=0.004)$, and physical function $(22.5$ vs. $17.3 ; 95 \% \mathrm{CI}-9.3$ to -1.3 ; $\mathrm{p}=0.007)$ ] and with pain [pain (24.0 vs. $19.2 ; 95 \% \mathrm{CI}-8.9$ to $-0.7 ; \mathrm{p}=0.016)]$ and stiffness [(23.8 vs. $19.4 ; 95 \%$ CI-8.7 to $-0.1 ; \mathrm{p}=0.044)]$ compared to GC. Significant reduction in mean VAS score was also observed in comparison to both placebo (22.6 vs. $17.0 ; 95 \% \mathrm{CI}-9.5$ to $-1.8 ; \mathrm{p}=0.002)$ and $\mathrm{GC}(22.6$ vs. $18.4 ; 95 \% \mathrm{CI}-8.0$ to $-0.4 ; \mathrm{p}=0.025)$. Significantly lesser number of patients required rescue medication in the undenatured type II 
collagen than placebo (11 vs 28, $\mathrm{p}=0.001)$. Safety assessments revealed maximum adverse events (AE) in GC group and 14/45 AEs were considered possibly related to GC. In undenatured type II collagen, eight AEs occurred and were considered to be not related to supplementation. This study demonstrates that compared to glucosamine and chondroitin sulphate, undenatured type II collagen is a safe and efficacious supplement in OA. ${ }^{8}$

Table 1: Clinical studies of undenatured type II collagen.

\begin{tabular}{|c|c|c|c|c|c|}
\hline $\begin{array}{l}\text { Author } \\
\text { (year) }\end{array}$ & Design & $\begin{array}{l}\text { Sample size and } \\
\text { study groups }\end{array}$ & Population & Duration & Major findings \\
\hline $\begin{array}{l}\text { Lugo et } \\
\text { al }^{59}\end{array}$ & $\mathrm{RCT}$ & $\begin{array}{l}55 \text { subjects } \\
\text { Placebo }(\mathrm{n}=28) \\
\text { or } \mathrm{U}-\mathrm{II}-\mathrm{C}(40 \\
\mathrm{mg} / \mathrm{d}, \mathrm{n}=27)\end{array}$ & $\begin{array}{l}\text { Healthy subjects } \\
\text { without prior } \\
\text { history of arthritic } \\
\text { disease or joint } \\
\text { pain at rest but } \\
\text { experienced joint } \\
\text { discomfort with } \\
\text { physical activity }\end{array}$ & 120 days & $\begin{array}{l}\text { U-II-C associated with significant improvement } \\
\text { in } \\
\text { - } \\
\text { - } \quad \text { placebo }\left(81.0 \pm 1.3^{\circ} \text { vs } 74.0 \pm 2.2^{\circ} ; p=0.011\right) \\
\text { - } \quad \text { baseline }\left(81.0 \pm 1.3^{\circ} \text { vs } 73.2 \pm 1.9^{\circ} ; \mathrm{p}=0.002\right) \text {. } \\
\text { - longer exercise period before experiencing } \\
\text { any initial joint discomfort compared to } \\
\text { baseline }(2.8 \pm 0.5 \text { vs } 1.4 \pm 0.2 \text { min } p=0.019) \\
\text { No product related AEs. }\end{array}$ \\
\hline $\begin{array}{l}\text { Crowley } \\
\text { et } \text { al }^{7}\end{array}$ & $\mathrm{RCT}$ & $\begin{array}{l}52 \text { patients } \\
\text { U-II-C }(n=26) \text { or } \\
\text { GC }(n=26)\end{array}$ & Knee OA & 90 days & $\begin{array}{l}\text { U-II-C vs GC } \\
\text { - } \quad \text { WOMAC score reduction: } 33 \% \text { vs } 14 \% \\
\text { - } \quad \text { VAS score reduction: } 40 \% \text { vs } 15.4 \% \\
\text { - } \quad \text { LFI score reduction: } 20 \% \text { vs } 6 \% \\
\text { - } \quad \text { AEs } \\
\text { Potal: } 35 \text { vs } 58 \\
\text { Possibly related to supplement: } 11.4 \% \text { vs } 23 \%\end{array}$ \\
\hline $\begin{array}{l}\text { Lugo et } \\
\text { al }^{8}\end{array}$ & RCT & $\begin{array}{l}190 \text { patients } \\
\text { U-II-C }(40 \\
\text { mg/d) or } \\
\text { GC }(1500 \& \\
1200 \mathrm{mg}) \text { or } \\
\text { Placebo }\end{array}$ & Knee OA & 180 days & $\begin{array}{l}\text { U-II-C associated with significant reduction in } \\
\text { - } \quad \text { overall WOMAC score vs placebo } \\
\text { ( } \mathrm{p}=0.002) \text { and } \mathrm{GC}(\mathrm{p}=0.04) \text {. } \\
\text { - } \quad \text { all three WOMAC subscales: } \\
\text { - } \mathrm{GC} \text { ) } \\
\text { - } \quad \text { stiffness ( } \mathrm{p}=0.0003 \text { vs. placebo; } \mathrm{p}=0.016 \mathrm{vs.} \text { vs. placebo; } \mathrm{p}=0.044 \text { vs. } \\
\text { GC); } \\
\text { - } \quad \text { physical function ( } \mathrm{p}=0.007 \text { vs. placebo) } \\
\text { AEs } \\
\text { - } 8 \text { with U-II-C, deemed not related to } \\
\text { supplementation } \\
\text { - } 45 \text { with GC, } 14 \text { possible events linked to } \\
\text { GC } \\
\text { 9 with placebo, } 1 \text { possible event linked to } \\
\text { placebo }\end{array}$ \\
\hline $\begin{array}{l}\text { Lerman } \\
\text { et } \text { al }^{60}\end{array}$ & $\begin{array}{l}\text { Case } \\
\text { series }\end{array}$ & $\begin{array}{l}17 \text { patients } \\
\text { Two tablets of } \\
\text { nTHIAA + U-II- } \\
\text { C } 2 \times / \text { d with } \\
\text { meals }\end{array}$ & $\begin{array}{l}13 \text { patients with } \\
\text { probable OA } 4 \\
\text { patients with } \\
\text { possible RA }\end{array}$ & 12 weeks & $\begin{array}{l}\text { The combination treatment was associated with } \\
\text { significant reduction in } \\
\text { - } \quad \text { VAS score: } 4.18 \pm 0.61 \text { to } 1.43 \pm 0.68 \\
\text { ( }<<0.05) \\
\text { - } \quad \text { Total MSQ score: } 18.38 \pm 2.87 \text { to } 7.85 \pm 2.05 \\
\text { ( }<<0.01) \\
\text { - HAQ-DI score: } 60.23 \pm 6.47 \text { to } 20.54 \pm 6.38 \\
\text { ( }<0.001) \\
\text { AIQ daily living score: } 23.79 \pm 2.55 \text { to } \\
\text { 8.36 } \pm 2.99 \text { ( }<<0.001) \\
\text { AIMS2 score: } 6.08 \pm 0.54 \text { to } 3.27 \pm 0.70\end{array}$ \\
\hline
\end{tabular}




\begin{tabular}{|c|c|c|c|c|c|}
\hline $\begin{array}{l}\text { Author } \\
\text { (year) }\end{array}$ & Design & $\begin{array}{l}\text { Sample size and } \\
\text { study groups }\end{array}$ & Population & Duration & Major findings \\
\hline $\begin{array}{l}\text { Mehra } \\
\text { et al }\end{array}$ & $\begin{array}{l}\text { Open } \\
\text { label }\end{array}$ & $\begin{array}{l}219 \text { patients } \\
\text { U-II-C } 40 \mathrm{mg} / \mathrm{d}\end{array}$ & Knee OA & 90 days & $\begin{array}{l}\text { U-II-C associated with significant reduction in } \\
\text { WOMAC score: mean change: }-20.7 \pm 12.6 \text {, } \\
\quad(p<0.0001) \text {, } \\
\text { VAS score: mean change: }-3.3 \pm 1.8, \\
\quad(p<0.0001) \\
\text { At least one TEAE: } 4.47 \% \\
\text { No serious AEs or AEs that resulted in } \\
\text { termination of study medication }\end{array}$ \\
\hline
\end{tabular}

AEs: adverse events, AIMS2: arthritis impact measurement scales 2, AIQ: arthritis impact questionnaire, GC: glucosamine HCl + chondroitin sulfate, HAQ-DI: health assessment questionnaire, LFI: Lequesne's functional index, MSQ: medical symptoms questionnaire, OA: osteoarthritis, TEAE: treatment emergent adverse event, THIAA: Tetrahydro iso- $\alpha$ acids, VAS: visual analogue scale, U-II-C: undenatured type II collagen, WOMAC: Western Ontario McMaster Osteoarthritis Index.

A recent post-marketing surveillance study from India in 291 patients with OA reported significant reduction in WOMAC score (mean change: $-20.7 \pm 12.6,(\mathrm{p}<0.0001)$ ), and VAS score (mean change: $-3.3 \pm 1.8,(\mathrm{p}<0.0001)$ ) at day 90. Also, there was reduction in WOMAC pain, stiffness and physical function subscales score from day 30 to day 90. At least one treatment emergent adverse event (TEAE) was reported in $4.47 \%$ patients with nausea $(1.37 \%)$ and headache $(1.03 \%)$ being the common AEs. This suggests that undenatured collagen type II is effective and safe in patients with OA. ${ }^{61}$

\section{Advantages of collagen in $\mathrm{OA}$}

The current available evidence with undenatured collagen type II in treatment of OA shows that it

- $\quad$ increases the functionality and mobility of the joints and results in pain reduction ${ }^{10,62}$

- influences the humoral and cellular immune response through the T-regulatory cell secreting cytokines such as IL-10 and transforming growth factors.

- inhibits the immune response to collagen type II present in the extracellular matrix of the articular cartilage. ${ }^{13,63}$

- prevents the proinflammatory exaggerated reaction of the immune system against the articular cartilage in patients with OA. ${ }^{64}$

\section{Place in therapy}

Therapies that confer a cessation or inhibition of structural deterioration of joint pathologies are highly desirable in current scenario. Undenatured type II collagen is a new and a potential option to prevent or reduce the joint destruction, pain and loss of function by a mechanism of immune tolerance that avoids T-cells attack on collagen fibres in joints. Current evidence suggests use of structure-modifying therapy such as undenatured type II collagen as adjuvant to or supplement to current oral pharmacological therapies in short- and long-term treatment of OA. Given its safety and efficacy, undenatured type II collagen should be considered as choice of agent in early as well as in late part of the disease to prevent or reduce the further joint destruction. Provided with ability to alter disease pathogenesis, undenatured type II collagen holds a strong proposition for one and all with OA.

\section{CONCLUSION}

A variety of adjuvants are being currently used in management of OA with varying clinical efficacy among different studies. With the strong patho-physiological basis of mechanistic role and joint stress improvements demonstrated in numerous experimental models, in healthy individuals and in OA patients, undenatured type II collagen appear to be of crucial importance in management of OA. Collagen-based therapies owing to their efficacy and additional advantage of minimal adverse effects seem to be promising in comparison with current mainstream NSAIDs and other analgesics. Given the current burden of disease with poor quality of life in OA, undenatured type II collagen seems to be an attractive candidate for OA treatment that can supplement the existing therapies for potentially better outcomes and also bridge the therapeutic gap as a safe and effective option in patients who are intolerant or are at risk to other anti-inflammatory agents.

\section{ACKNOWLEDGEMENTS}

We thank Dr Vijay Katekhaye for his support in preparation and reviewing of the manuscript.

Funding: No funding sources

Conflict of interest: Authors Sanjay Kamble, Hiten Saresa and Rishi Jain are salaried employees of the Wockhardt Ltd., BKC, Mumbai. Other authors declare no conflict of interest

Ethical approval: Not required

\section{REFERENCES}

1. Flores RH, Hochberg MC. In Osteoarthritis. In: Brandt KD, Doherty M, Lohmander LS, eds. Oxford Univ. Press, 2003; pp: 1-8. 
2. Sellam J, Berenbaum F. Is osteoarthritis a metabolic disease? Joint Bone Spine. 2013;80:568-73.

3. Pelletier MJ, Wildi LM, Pelletier JP. Future therapeutics for osteoarthritis. Bone. 2012;51:297311.

4. Spector TD, Cooper C. Radiographic assessment of osteoarthritis in population studies:whither Kellgren and Lawrence? Osteoarthritis Cartilage. 1993;1:203-6.

5. Chen D, Shen J, Zhao W, Wang T, Han L, Hamilton $\mathrm{JL}$, et al. Osteoarthritis: toward a comprehensive understanding of pathological mechanism. Bone Res. 2017;5:16044.

6. Laupattarakasem W, Laopaiboon M, Laupattarakasem P, Sumananont C. Arthroscopic debridement for knee osteoarthritis. Cochrane Database of Syst Rev. 2008;1:CD005118.

7. Crowley DC, Lau FC, Sharma P, Evans M, Guthrie N, Bagchi M. Safety and efficacy of undenatured type II collagen in the treatment of osteoarthritis of the knee: a clinical trial. Int J Med Sci. 2009;6:31221.

8. Lugo JP, Saiyed ZM, Lane NE. Efficacy and tolerability of an undenatured type II collagen supplement in modulating knee osteoarthritis symptoms: A multicenter randomized, double-blind, placebo-controlled study. Nutr J. 2016;15:14.

9. Guccione AA, Felson DT, Anderson JJ, Anthony JM, Zhang Y, Wilson PW, et al. The effects of specific medical conditions on the functional limitations of elders in the Framingham Study. Am J Public Health. 1994;84:351-8.

10. Zhu P, Li XY, Wang HK, Jia JF, Zheng ZH, Ding J, et al. Oral administration of type-II collagen peptide 250-270 suppresses specific cellular and humoral immune response in collagen-induced arthritis. Clin Immunol. 2007;122:75-84.

11. Lozano R, Naghavi M, Foreman K, Lim S, Shibuya $\mathrm{K}$, Aboyans V, et al. Global and regional mortality from 235 causes of death for 20 age groups in 1990 and 2010:a systematic analysis for the Global Burden of Disease Study 2010. Lancet. 2012;380:2095-128.

12. Priority disease and reasons for inclusion. Osteoarthritis. Available at: https://www.who.int/ medicines/areas/priority_medicines/Ch6_12Osteo.p df. Accessed on 3 January 2019.

13. Pal CP, Singh P, Chaturvedi S, Pruthi KK, Vij A. Epidemiology of knee osteoarthritis in India and related factors. Indian J Orthop. 2016;50(5):518-22.

14. Suri S, Walsh DA. Osteochondral alterations in osteoarthritis. Bone. 2012;51:204-11.

15. Scanzello CR, Goldring SR. The role of synovitis in osteoarthritis pathogenesis. Bone. 2012;51:249-57.

16. Wang $\mathrm{X}$, Hunter $\mathrm{D}, \mathrm{Xu} \mathrm{J}$, Ding C. Metabolic triggered inflammation in osteoarthritis. Osteoarthritis Cartilage. 2015;23:22-30.

17. Malfait AM. Osteoarthritis year in review 2015:biology. Osteoarthritis Cartilage. 2016;24:216.
18. Yang X, Chen L, Xu X, Li C, Huang C, Deng CX. TGF- $\beta /$ Smad3 signals repress chondrocyte hypertrophic differentiation and are required for maintaining articular cartilage. J Cell Biol. 2001;153:35-46.

19. Musumeci G. The effect of mechanical loading on articular cartilage. J Funct Morphol Kinesiol. 2016;1:154-61.

20. Zhu M, Tang D, Wu Q, Hao S, Chen M, Xie C, et al. Activation of $\beta$-catenin signaling in articular chondrocytes leads to osteoarthritis-like phenotype in adult $\beta$-catenin conditional activation mice. J Bone Miner Res. 2009;24:12-21.

21. Thirunavukkarasu K, Pei Y, Wei T. Characterization of the human ADAMTS-5 (aggrecanase-2) gene promoter. Mol Biol Rep. 2007;34:225-31.

22. ANON. Recommendations for the medical management of osteoarthritis of the hip and knee: 2000 update. American College of Rheumatology Subcommittee on Osteoarthritis Guidelines. Arth Rheum. 2000;43:1905-15.

23. Fernandes L, Hagen KB, Bijlsma JW, Andreassen O, Christensen P, Conaghan PG, et al. EULAR recommendations for the non-pharmacological core management of hip and knee osteoarthritis. Ann. Rheum. Dis. 2013;72:1125-35.

24. Fransen M, McConnell S, Hernandez Molina G, Reichenbach S. Exercise for osteoarthritis of the hip. Cochrane Database Syst Rev. 2014;4:CD007912.

25. Zhang W, Nuki G, Moskowitz RW, Abramson S, Altman RD, Arden NK, et al. OARSI recommendations for the management of hip and knee osteoarthritis: part III: changes in evidence following systematic cumulative update of research published through January 2009. Osteoarthritis Cartilage. 2010;18:476-99.

26. Roberts E, Nunes VD, Buckner S, Latchem S, Constanti M, Miller P, et al. Paracetamol: not as safe as we thought? A systematic literature review of observational studies. Ann Rheum Dis. 2016;75:552-9.

27. Singh JA, Noorbaloochi S, MacDonald R, Maxwell LJ. Chondroitin for osteoarthritis. Cochrane Database Syst Rev. 2015;1:CD005614.

28. Bruyère $\mathrm{O}$, Cooper C, Pelletier JP, Branco J, Brandi ML, Guillemin F, et al. An algorithm recommendation for the management of knee osteoarthritis in Europe and internationally:a report from a task force of the European Society for Clinical and Economic Aspects of Osteoporosis and Osteoarthritis (ESCEO). Semin Arthritis Rheum. 2014;44:253-63.

29. di Padova C. S-adenosylmethionine in the treatment of osteoarthritis. Review of the clinical studies. Am J Med. 1987;83:60-5.

30. Najm WI, Reinsch S, Hoehler F, Tobis JS, Harvey PW. S-adenosyl methionine (SAMe) versus celecoxib for the treatment of osteoarthritis 
symptoms:a double-blind cross-over trial.[ISRCTN36233495]. BMC Musculoskeletal Disorders. 2004;5:6.

31. Clegg DO, Reda DJ, Harris CL, Klein MA, O’Dell JR, Hooper MM, et al. Glucosamine, Chondroitin Sulfate, and the Two in Combination for Painful Knee Osteoarthritis. N Engl J Med. 2006;354:795808.

32. Zhu $\mathrm{X}$, Sang $\mathrm{X}$, Wu $\mathrm{D}$, Ring J, Jiang $\mathrm{L}$. Effectiveness and safety of glucosamine and chondroitin for the treatment of osteoarthritis:a meta-analysis of randomized controlled trials. J Orthop Surg Res. 2018;13:170.

33. Yimam M, Horm $\mathrm{T}$, Wright L, Jiao P, Hong M, Brownell L, et al. Cartilage Protection and Analgesic Activity of a Botanical Composition Comprised of Morus alba, Scutellaria baicalensis, and Acacia catechu. Evidence-Based Complementary Alternative Med. 2017:7059068.

34. Arjmandi BH, Omsbee LT, Elam ML, Campbell SC, Rahnama N, Payton ME, et al. A Combination of Scutellaria Baicalensis and Acacia Catechu Extracts for Short-Term Symptomatic Relief of Joint Discomfort Associated with Osteoarthritis of the Knee. J Med Food. 2014;17:707-13.

35. Hashempur MH, Sardneshin S, Mosavat SH, Ashraf A. Green tea (Camellia sinensis) for patients with knee osteoarthritis:A randomized open-label activecontrolled clinical trial. Clin Nutr. 2018;37:85-90.

36. Panahi Y, Rahimnia AR, Sharafi M, Alishiri G, Saburi A, Sahebkar A. Curcuminoid Treatment for Knee Osteoarthritis: A Randomized Double-Blind Placebo-Controlled Trial. Phytother Res. 2014;28:1625-31.

37. Ying X, Chen X, Cheng S, Shen Y, Peng L, Xu HZ. Piperine inhibits IL- $\beta$ induced expression of inflammatory mediators in human osteoarthritis chondrocyte. Int Immunopharmacol. 2013;17:2939.

38. Siddiqui MZ. Boswellia serrata, a potential antiinflammatory agent:an overview. Indian J Pharm Sci. 2011;73(3):255-61.

39. Suva MA, Kheni DB, Sureja VP. Management strategies for knee osteoarthritis:Aflapin ${ }^{\circledR}$ (Boswellia serrata extract). Ayu. 2017;38(1-2):94.

40. Ramakanth GS, Uday Kumar C, Kishan PV, Usharani P. A randomized, double blind placebocontrolled study of efficacy and tolerability of Withaina somnifera extracts in knee joint pain. J Ayurveda Integr Med. 2016;7(3):151-7.

41. Bartels EM, Folmer VN, Bliddal H, Altman RD, Juhl C, Tarp S, Zhang W, Christensen R. Efficacy and safety of ginger in osteoarthritis patients:a metaanalysis of randomized placebo-controlled trials. Osteoarthritis Cartilage. 2015 Jan;23(1):13-21.

42. Boe C, Vangsness CT. Fish Oil and Osteoarthritis: Current Evidence. Am J Orthop (Belle Mead NJ). 2015;44:302-5.

43. Hill CL, March LM, Aitken D, Lester SE, Battersby R, Hynes K, et al. Fish oil in knee osteoarthritis:a randomised clinical trial of low dose versus high dose Ann Rheum Dis. 2016;75:23-9.

44. Bohlooli S, Jastan M, Nakhostin-Roohi B, Mohammadi S, Baghaei Z. A pilot double-blinded, randomized, clinical trial of topical virgin olive oil versus piroxicam gel in osteoarthritis of the knee. J Clin Rheumatol. 2012;18:99-101.

45. Christiansen BA, Bhatti S, Goudarzi R, Emami S. Management of Osteoarthritis with Avocado/Soybean Unsaponifiables. Cartilage. 2015;6:30-44.

46. Maheu E, Cadet C, Marty M, Moyse D, Kerloch I, Coste P, et al. Randomised, controlled trial of avocado-soybean unsaponifiable (Piascledine) effect on structure modification in hip osteoarthritis: the ERADIAS study. Ann Rheum Dis. 2014;73(2):376-84.

47. Poole AR. Cartilage in health and disease. In: Koopman W, ed. Arthritis and allied conditions. A textbook of rheumatology. 14th Ed. Philadelphia: Lippincott, Williams and Wilkins; 2001: 226-284.

48. Poole AR, Rosenberg LC, Reiner A, Ionescu M, Bogoch E, Roughley PJ. Contents and distributions of the proteoglycans decorin and biglycan in normal and osteoarthritic human articular cartilage. J Orthop Res. 1996;14:681-9.

49. Hollander AP, Heathfield TF, Webber C, Iwata Y, Rorabeck C, Bourne R, et al. Increased damage to type II collagen in osteoarthritic cartilage detected by a new immunoassay. $J$ Clin Inves. 1994;93:1722-32.

50. van Vijven JP, Luijsterburg PA, Verhagen AP, van Osch GJ, Kloppenburg M, Bierma-Zeinstra SM. Symptomatic and chondroprotective treatment with collagen derivatives in osteoarthritis:a systematic review. Osteoarthritis Cartilage. 2012;20:809-21.

51. Kyung-Su P, Min-Jung P, Mi-La C, Seung-Ki K, JiHyeon J, Hyeok-Jae K, et al. Type II collagen oral tolerance;mechanism and role in collagen-induced arthritis and rheumatoid arthritis. Mod Rheumatol. 2009;19:581-9.

52. Tong T, Zhao W, Wu YQ, Chang Y, Wang QT, Zhang LL, et al. Chicken type II collagen induced immune balance of main subtype of helper T cells in mesenteric lymph node lymphocytes in rats with collagen-induced arthritis. Inflamm Res. 2010;59:369-77.

53. Weiner HL, da Cunha AP, Quintana F, Wu H. Oral tolerance. Immunol Rev. 2011;241:241-59.

54. Li MO, Flavell RA. TGF-beta: a master of all T cell trades. Cell. 2008;134:392-404.

55. Coombes JL, Siddiqui KR, Arancibia-Cárcamo CV, Hall J, Sun CM, Belkaid Y, et al. A functionally specialized population of mucosal CD103+ DCs induces Foxp3+ regulatory $\mathrm{T}$ cells via a TGF-beta and retinoic acid-dependent mechanism. J Exp Med. 2007;204:1757-64.

56. Ilan Y, Zigmond E, Lalazar G, Dembinsky A, Ya'acov AB, Hemed N, et al. Oral administration of OKT3 monoclonal antibody to human subjects 
induces a dose-dependent immunologic effect in $\mathrm{T}$ cells and dendritic cells. J Clin Immunol. 2010;30:167-77.

57. Bagi CM, Berryman ER, Teo S, Lane NE. Oral administration of undenatured native chicken type II collagen (UC-II) diminished deterioration of articular cartilage in a rat model of osteoarthritis (OA). Osteoarthritis Cartilage. 2017;25:2080- 90.

58. Di Cesare Mannelli L, Micheli L, Zanardelli M, Ghelardini C. Low dose native type II collagen prevents pain in a rat osteoarthritis model. BMC Musculoskeletal Disorders. 2013;14:228.

59. Lugo JP, Saiyed ZM, Lau FC, Molina JPL, Pakdaman MN, Shamie AN. Undenatured type II collagen (UC-II®) for joint support:a randomized, double-blind, placebo-controlled study in healthy volunteers. J Int Society Sports Nutr. 2013;10:48.

60. Lerman et al. Nutritional Approach for Relief of Joint Discomfort in a form of A 12-week, Opencase Series and Illustrative Case Report. Integr Med (Encinitas). 2015;14:52-61.

61. Mehra A, Anand P, Borate M, Paul P, Kamble S, Mehta KD, et al. A non-interventional, prospective, multicentric real life Indian study to assess safety and effectiveness of un-denatured type 2 collagen in management of osteoarthritis. Int J Res Orthop. 2019;5:315-20.

62. Gupta RC, Canerdy TD, Lindley J, Konemann M, Minniear J, Carroll BA, et al. Comparative therapeutic efficacy and safety of type-II collagen (UC-II®), glucosamine and chondroitin in arthritic dogs:Pain evaluation by ground force plate. J Anim Physiol Anim Nutr. 2012;96:770-7.

63. Park KS, Park MJ, Cho ML, Kwok SK, Ju JH, Ko HJ, et al. Type II collagen oral tolerance:Mechanism and role in collagen-induced arthritis and rheumatoid arthritis. Mod. Rheumatol. 2009;19:581-9.

64. Lopez HL. Nutritional interventions to prevent and treat osteoarthritis-Part II:Focus on micronutrients and supportive nutraceuticals. PM R. 2012;4:S155S168.

Cite this article as: Kakatkar V, Pal AK, Reddy R, Dashputra R, Kamble S, Saresa H, et al. Adjuvant drugs in management of osteoarthritis: spotlight on type II collagen. Int J Res Orthop 2019;5:753-63. 